\title{
Verdade é práxis: Nietzsche e Marx ${ }^{* * *}$
}

\author{
Helmut Heit***
}

Resumo: O objetivo deste artigo é delinear semelhanças significativas e dissonâncias produtivas entre Marx e Nietzsche. Minha tese é a de que esses dois pensadores têm muito mais em comum do que é reconhecido ordinariamente. Após provar que Nietzsche muito provavelmente conhecia Marx, eu desenvolvo vários aspectos comuns a ambos. Ambos os pensadores perseguem projetos filosóficos de transformação crítica, empregam uma hermenêutica da suspeita, além do bem e do mal, ambos propõem uma antropologia naturalizada e reconstruções históricas. As passagens finais discutem suas respectivas concepções de capitalismo e de socialismo. As semelhanças e as diferenças entre Nietzsche e Marx podem servir como recurso produtivo e como inspiração em nossas tentativas contemporâneas para entender o mundo em que vivemos.

Palavras-chave: verdade, prática, liberdade, transformação, capitalismo, socialismo

\footnotetext{
* This research is supported by the 'Double First Class' development project of Tongji University, Shanghai

** Tradução de Saulo Krieger. Revisão de Clademir Araldi.

*** Professor da Universidade Tongji, Xangai/China.

Correio eletrônico: heit@tongji.edu.cn
} 
Heit, H.

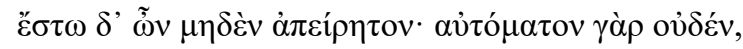

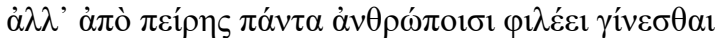

Não vamos deixar nada por tentar; pois nada acontece por si mesmo, porém toda a humanidade deseja emergir de tentativas. (Heródoto, Histórias, VII, 9)

\section{Nietzsche e Marx?}

A conjunção entre Marx e Nietzsche é uma petitio principii. É claro que é sempre possível dispor dois objetos numa relação arbitrariamente comparativa, mas será isso produtivo ou pelo menos promissor? Não seriam esses pensadores por demais diferentes, para não dizer incompatíveis ou mesmo incomensuráveis, para se justificar a conexão próxima sugerida pela palavra "e"? Pode-se imaginar que Marx e Nietzsche se contradizem de tantas maneiras substanciais que estaremos mais comparando maçãs com bananas. Além disso, Marx e Nietzsche jamais se conheceram um ao outro. No caso de Marx isso pouco surpreende: Marx e sua mulher se mudaram para Paris em outubro de 1843, um ano antes do nascimento de Nietzsche, e Marx permaneceu fora do mundo de língua alemã durante a maior parte da vida. Dada a sua situação biográfica, como por seus interesses políticos, culturais e científicos, é escassa a probabilidade de que ele pudesse desenvolver interesses culturais e científicos, há escassa probabilidade de que ele desenvolveria interesse por um autor amplamente ignorado, e ademais ele morreu em 1883, antes que Nietzsche se tornasse importante. Não tenho conhecimento de qualquer evidência de que Marx tenha sequer conhecido o nome de Nietzsche.

Avaliar o conhecimento que Nietzsche teria de Marx já é um pouco mais complicado. Nietzsche em momento algum menciona Marx ou o marxismo em seus escritos. Já de há muito se tem assumido, por exemplo, por Mazzino Montinari, que Nietzsche não tinha basicamente nenhum conhecimento de Marx "e jamais chegou a ter conhecimento 
dos termos 'marxismo' ou 'materialismo histórico"' 1 Contudo, um estudo detalhado da leitura de Nietzsche veio a sugerir, de modo convincente, ser muito provável que Nietzsche tivesse relativamente boa familiaridade com algumas ideias básicas do marxismo². Marx e suas ideias aparecem em diversos livros de Nietzsche adquiridos ou tomados de empréstimo de bibliotecas. Precisamente a Geschichte der Nationalökonomie, de Eugen Dühring, de 1875, contém um resumo extenso, crítico, porém honesto, da contribuição à economia política de Marx. Contudo, as passagens em questão na cópia do livro de Nietzsche (pp. 493-507) não trazem anotações nem outra evidência de terem sido lidas por Nietzsche. Mas recentemente eu descobri uma discussão sobre Marx, acompanhada de sua defesa, em outro livro possuído por Nietzsche: Leopold Jacoby, Die Idee der Entwickelung. Eine sozial-philosophische Darstellung ${ }^{3}$. Jacoby introduz a obra de Marx nas primeiras páginas de seu estudo e o põe em pé de igualdade com Darwin, muito embora sua obra tenha passado despercebida por um bom tempo. E ao final de uma longa citação da Crítica da economia política, de 1859, o nome de Karl Marx está sublinhado a lápis, o que provavelmente teria sido feito por Nietzsche ${ }^{4}$ :

schaffen zugleich die materiellen Bedingungen zur Lösung dieses Antagonismus. Mit dieser Gesellschaftsformation schliesst daher die Vorgeschichte der menschlichen Gesellschaft ab.

Zur Kritik der politischen Oekonomie von Karl Marx. Erstes Heft. Berlin 1859. Seite VI.

Fig. 1. Reprodução da imagem da página do livro de Leopold Jacoby, Die Idee der Entwickelung. Eine sozial-philosophische Darstellung, p. 15, do exemplar da Biblioteca pessoal de Nietzsche que se encontra na Herzogin Anna Amalia Bibliothek [HAAB], em Weimar, com a seguinte catalogação: HAAB C280[-1].

1 Montinari, 1982, p. 194.

2 Cf. Brobjer, 2002.

3 Cf. Campioni et. al., 2003, p. 318. Nietzsche adquiriu a segunda edição (la. parte) da obra de Jacoby supramencionada. Cf. Jacoby, 1886. Esse exemplar da Biblioteca pessoal de Nietzsche encontra-se na Herzogin Anna Amalia Bibliothek [HAAB], em Weimar com a seguinte catalogação: HAAB C280[-1].

4 Jacoby, 1886, p. 15.

Cad. Nietzsche, Guarulhos/Porto Seguro, v.39, n.3, p. 141-174, setembro/dezembro, 2018. 
Heit, H.

A segunda e mais substancial razão pela qual as pessoas raramente falam de Nietzsche e Marx é a de que esses dois pensadores são frequentes vezes vistos em estrita contradição. Eles aparecem como alternativas excludentes. Um bom exemplo dessa visão é uma observação feita pelo intelectual chinês Liang Qichao, em seu Journal of Peoples Renovation (新民叢報), em 1902. Ele se refere ao filósofo evolucionista britânico, hoje amplamente desconhecido, Benjamin Kidd, e seus Principles of Western Civilisation, publicado em 1902. Liang resume a concepção de Kidd desse modo: “As escolas de pensamento mais influentes na Alemanha até hoje são o socialismo de Marx e o individualismo de Nietzsche"5. Essa observação não é somente traço característico da recepção ampla desses dois pensadores; ela é também a primeira menção a Nietzsche em uma publicação chinesa. Nietzsche como proponente da individualidade solitária e da existência heroica, Marx como teórico da igualdade social e das massas. Eu me referi a Kidd como exemplo de tais leituras, uma vez que essa mesma passagem foi citada num ensaio intitulado Kidd: A Revolutionary of Evolutionary Theory por Liang Qichao em seu Journal of Peoples Renovation, que por sua vez foi a primeira menção a Nietzsche em uma publicação chinesa. Pareceu-me como se se pudesse ser ou nietzschiano ou marxista, e Liang, sob a, digamos, desinformada impressão de que Kidd teria sido o filósofo bem-sucedido a evitar essas duas falsas alternativas. Mas esse não foi o único equívoco na história de Marx e Nietzsche. A construção simplificadora do individualismo nietzschiano e do socialismo marxista já em 1902 aponta para lutas e debates ideológicos e políticos nas décadas vindouras do século XX. Os nomes desses dois pensadores não raro têm servido como emblemas e brasões de facções opostas. Relata-se que Max Weber teria dito a seus alunos em 1920, após ter assistido a uma conferência de Oswald Spengler: "O mundo em que intelectualmente existimos hoje é um mundo

5 Kidd, 1902.

144 | Cad. Nietzsche, Guarulhos/Porto Seguro, v.39, n.3, p. 141-174, setembro/dezembro, 2018. 
formado essencialmente por Marx e Nietzsche". Não deixa de ser verdade, mas não porque, de modo paradigmático, eles expressem os dois extremos alternativos da modernidade. Como diz Weber, ambos formaram nosso mundo intelectual, foram responsáveis por parcelas substanciais de nosso léxico, de nossas questões, de nossas avaliações ou esperanças e medos; contribuíram de maneira significativa para nossas tentativas de nos orientarmos no mundo em que vivemos. A Marx e Nietzsche não se pode atribuir tamanha atualidade por realmente terem formado nosso mundo real, mas porque eles esperam que tenhamos compreendido este mundo. Encontraram expressões fortes para observações sensatas acerca de forças e problemas que ainda dão forma ao mundo de hoje. Por essa razão, trazer em conjunto esses dois pensadores tem um elevado potencial para melhorar, inspirar e iluminar nossa ambição de compreender o nosso mundo.

Infelizmente, contudo, tanto Marx quanto Nietzsche não raro serviram como meras etiquetas, slogans, como balizas e espantalhos de posições admiradas ou odiadas. Objetos de adoração por seus seguidores e instrumentos de política identitária de demarcação por seus oponentes. A maior parte dos nietzschianos ignorava Marx e a maior parte dos representantes do marxismo foram críticos a Nietzsche desde o início. Frans Mehring, por exemplo, definiu Nietzsche como oponente político e intelectual já em 1891 e chamou-o de "filósofo social do capitalismo"7. Georg Lukács ${ }^{8}$ tornou-se proverbial por sustentar que Nietzsche foi responsável por Hitler, muito embora sua interpretação de Nietzsche mereça atenção mais cuidadosa para além desse cliché. A esse respeito vale notar que Thomas Mann teria dito que o Übermensch de Nietzsche nada mais é do que a idealização do Führer fascista, e que o próprio filósofo, com seu filosofar inteiro, teria atuado como um marcapasso, cocriador e promotor de ideias para

6 Weber, 1920, p. 555.

7 Mehring, 1891, p. 188.

8 Lukács, 1954, p. 7-87; 1966, p. 27-101.

Cad. Nietzsche, Guarulhos/Porto Seguro, v.39, n.3, p. 141-174, setembro/dezembro, 2018. 
Heit, H.

o - fascismo global europeu"9. Tais acusações são simplificadoras, anacrônicas e inúteis: simplificadoras, para dizer o mínimo, quando não completamente desviantes, por não fazerem justiça aos textos; anacrônicas, pois tomam Nietzsche como responsável por fatos e feitos já bem posteriores, os quais o autor do Zaratustra não poderia antecipar nem mesmo em seus maiores arroubos de imaginação; e são inúteis por impossibilitar qualquer diálogo produtivo entre Nietzsche e Marx. Felizmente, o século XXI nos permite empreender enlaces mais relaxados e honestos para com esses dois pensadores.

Um primeiro exemplo de uma avaliação muito mais promissora é o texto Observações sobre o Nietzsche de Jaspers, de Max Horkheimer. Em 1937, no exílio e plenamente consciente da adoção não muito convicta de Nietzsche por alguns influentes nacional-socialistas, Horkheimer defende Nietzsche contra o que ele considera uma trivialização pequeno-burguesa da parte de Karl Jaspers. Em vez de domesticar de Nietzsche como um pensador contemplativo de problemas autênticos e existenciais, porém remotos, Horkheimer invoca seu potencial como um crítico a ser levado a sério: "Não se pode falar em Nietzsche sem relacioná-lo claramente à realidade"10. Isso pode incluir ideias essenciais de Nietzsche, que parecem contradizer uma perspectiva marxista como a de Horkheimer. $\mathrm{O}$ diretor do Instituto de Pesquisa Social de Frankfurt nos convida a reconsiderar até mesmo o conceito de Übermensch como um ideal social: "o além-do-homem ou será muitos, ou não será nenhum”. O próprio Nietzsche pode não ter pensado dessa maneira, já que, ao contrário de Marx, não conseguia imaginar um mundo para além da exploração. Mas Horkheimer prossegue afirmando que, muito embora Nietzsche tenha compreendido mal o "caráter histórico do trabalho" em seu ódio contra um "mundo dominado pela economia",

9 Mann, 1947, p. 33; cf. Brown, 2018.

10 Horkheimer, 1937, p. 414.

146 Cad. Nietzsche, Guarulhos/Porto Seguro, v.39, n.3, p. 141-174, setembro/dezembro, 2018. 
seu diagnóstico crítico do conformismo e do ressentimento ainda deve ser levado a sério ${ }^{11}$.

Muito embora mais adiante eu vá questionar a visão de Horkheimer sobre Nietzsche, eu o tenho por um modelo para a minha tentativa de trazer Marx e Nietzsche para uma conexão mais próxima. Minha tese é a de que esses dois pensadores têm muito mais em comum do que se costuma reconhecer. Além disso, quero indicar que tanto as semelhanças quanto as diferenças entre Marx e Nietzsche poderiam servir como recurso produtivo e inspiração para nossas tentativas contemporâneas de compreender o mundo em que vivemos. Tomando o meu próprio caso, vou propor algumas teses. Essas teses são preliminares e pensadas como convite e estímulo à investigação. As explicações e justificativas serão também de caráter sumário, uma vez que manterei o foco em semelhanças e dimensões nas quais ambos os pensadores possam enriquecer-se mutuamente. Argumentarei com mais detalhes nos casos em que a plausibilidade de minha afirmação me pareça menos óbvia. Por acaso, acabei por chegar a onze afirmações, mas sem pretender com isso qualquer semelhança adicional com as famosas teses de Marx sobre Feuerbach.

\section{Ambos compartilham a fama tardia de outsiders acadêmicos}

Em termos de biografia e com relação a sua origem social e familiar, Marx e Nietzsche não têm muito em comum. É possível encontrar semelhanças em âmbitos biográficos ou psicológicos, como o fato de serem particularmente talentosos ou por frustrarem expectativas da família, mas eu não as superestimaria. Creio ser mais informativo observar que ambos - embora por razões muito diferentes - não desenvolveram uma carreira acadêmica duradoura, apesar dos inícios muito promissores. Ambos desenvolveram sua

11 Horkheimer, 1937, p. 409.

Cad. Nietzsche, Guarulhos/Porto Seguro, v.39, n.3, p. 141-174, setembro/dezembro, 2018. 
Heit, H.

filosofia fora da academia e fora de círculos intelectuais estabelecidos e influentes, numa liberdade - não necessariamente escolhida por eles - de considerações e precauções acadêmicas e disciplinares. Eles buscaram amigos ou formaram ligas, mas não podiam fazer uso de redes abundantes, formar escolas e posicionar discípulos em posições influentes. Não obstante sua ambição, seu talento e trabalho árduo, mantiveram-se amplamente ignorados em vida e causaram relativamente pouco impacto em seus contemporâneos. Vale lembrar que Eduard von Hartmann ou Eugen Dühring, por exemplo, estiveram entre os intelectuais mais prolíficos e bem-sucedidos de seu tempo, enquanto Marx e Nietzsche eram lidos por poucos. Hartmann e Dühring são hoje conhecidos mais pelos ataques que lhes foram desferidos por Nietzsche, Marx e Engels. Mas à época ambos foram outsiders em diversos aspectos, e chegavam até mesmo a carecer de cidadania legal. Sua situação solitária coincide com a ambição de desenvolver suas visões particulares e distintas até as últimas consequências. Por isso surpreende pouco que Marx e Nietzsche jamais tenham conhecido um ao outro. A condição de outsider é a um só tempo causa e efeito de seu rigor intelectual.

Ao contrário da maioria dos outros outsiders, que não apenas se mostraram fiéis às suas perspectivas peculiares, mas também se mantiveram figuras arbitrárias e ignoradas, com quem ninguém se importa, tanto Marx quanto Nietzsche tornaram-se mundialmente famosos logo depois de sua morte (ou, da morte intelectual, no caso de Nietzsche), ao final do século XIX. Por certo que a obra de terceiros também se fez necessária para mover essas figuras da periferia para o centro do cenário intelectual. Ambos necessitaram do talento organizacional e mundano de terceiros, e ambos o encontraram, entre outros, em Friedrich Engels e Elisabeth Förster. Mas além dessas formas refinadas de publicação e propaganda, a obra tem de encontrar seus leitores. Tem de significar algo para muitos, a fim de produzir e impactar, como o fizeram Marx e Nietzsche. As

148 | Cad. Nietzsche, Guarulhos/Porto Seguro, v.39, n.3, p. 141-174, setembro/dezembro, 2018. 
visões de Marx e de Nietzsche podem ter sido idiossincráticas e peculiares, mas foram desenvolvidas, como sabemos, em estreita atenção à literatura, à pesquisa e aos debates de seu tempo. Eles apreenderam o seu tempo em pensamentos, e fizeram-no de maneira extraordinariamente iluminadora, inspiradora e produtiva. Marx e Nietzsche foram capazes de exercer enorme influência, ainda que tardia, porque foram observadores próximos e astutos, ainda que distanciados, dos aspectos essenciais de seu tempo. E sua atualidade em nosso tempo também resulta em boa parte do fato de que o mundo por eles analisado é ainda, em grau significativo, o mundo em que hoje vivemos. Diferentemente de muitos outsiders, suas concepções não eram especialmente limitadas ou esquisitas, mas traziam aspectos essenciais de nossa realidade e encontraram expressões que auxiliaram as gerações seguintes a expressarem a si próprias. É bem possível que ser um outsider, ser extemporâneo e estar "não envolvido" seja parte das condições para se ter perspectivas produtivas e inspiradoras.

\section{Ambos assumiram o papel polêmico de intelectuais públicos de viés crítico}

Ambos se engajaram como intelectuais públicos de viés crítico e se mostraram orgulhosos de sua pena afiada. Que Marx tenha resumido em si o papel de um intelectual público de viés crítico, isso costuma ser reconhecido e é algo bastante óbvio já com base em seus ensaios para o Rheinische Zeitung, por seu engajamento revolucionário e suas tentativas de estabelecer e influenciar movimentos políticos como a Liga dos Justos e a Liga Comunista. Mas o jovem Nietzsche igualmente intentava envolver-se com questões de interesse público de maneira crítica e reformatória, se se pensar em suas conferências Sobre o futuro de nossos estabelecimentos de ensino $(B A / E E)$. Algumas de suas primeiras publicações, como $O$ nascimento da tragédia ou Saudações pelo ano novo são pensadas para 
Heit, H.

servir à causa de Wagner e como apoio ao movimento reformatório cultural dos wagnerianos. Tanto Marx quanto Nietzsche dispenderam muitos esforços, provavelmente esforços demais, em delimitar suas concepções em relação às de outros, seja em A ideologia alemã e nos capítulos sobre os tipos errados de socialismo no Manifesto comunista, seja nas Considerações extemporâneas de Nietzsche: "As quatro Extemporâneas são integralmente guerreiras. Elas demonstram que eu não era nenhum 'João Sonhador', que me diverte desembainhar a espada - e talvez também que tenho o punho perigosamente destro" (EH/EH, "Por que escrevo livros tão bons", CI, § I). Quanto mais próxima possa parecer a conexão ou a semelhança, maior a avidez em enfatizar a diferença, ou em negligenciar e negar qualquer conexão que seja. Também vale observar que tanto Nietzsche quanto Marx mais tarde tomaram distância da atividade política imediata, ainda que por razões bem distintas, passando a centrar o foco mais na obra acadêmica, numa tentativa de estabelecer os fundamentos intelectuais para transformações posteriores.

\section{A cultura grega dos primórdios é o ponto de partida da emancipação (trágica)}

Ambos iniciaram a carreira com trabalhos sobre filosofia antiga, embora Marx não mostre um interesse duradouro pelos clássicos e certamente jamais desejou tornar-se um filólogo clássico. O fato de ele ter realizado seu doutorado sobre um tópico da Grécia antiga está essencialmente em consonância com os hábitos acadêmicos de seu tempo. Porém, ao revisar o tratamento dado a Epicuro, que à época era uma figura via de regra desvalorizada, ele defende uma posição até então pouco reconhecida. Contudo, outros planos para aprofundar esse tópico não se concretizaram ${ }^{12}$. O Nietzsche filósofo, por sua vez, também emergiu de seus primórdios clássicos.

12 Cf. Marx, 1843, p. 261.

150 | Cad. Nietzsche, Guarulhos/Porto Seguro, v.39, n.3, p. 141-174, setembro/dezembro, 2018. 


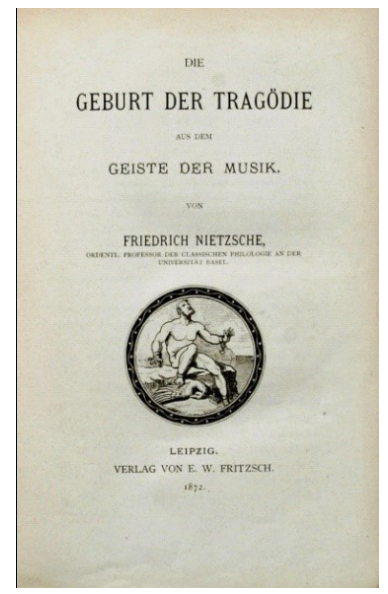

Fig. 2. Reprodução da capa da primeira edição de $O$ nascimento da tragédia, publicado em 1872.

Nisso, o mais interessante é que, tanto o Nietzsche de $O$ nascimento da tragédia quanto a tese de Marx sobre a diferença entre o emprego da filosofia natural por Demócrito e Epicuro, empregam o mito do Prometeu acorrentado. Ambos, com suas respectivas primeiras teses, posicionam-se na tradição do Titã arcaico, que se opõe à vontade egoísta dos deuses, e proporciona o fogo à humanidade, isto é, a ela proporciona técnicas e artes, inclusive a filosofia. Como punição para um ato que contribuiu decisivamente para libertar os seres humanos dos deuses, Prometeu foi preso às montanhas. Nietzsche encomendou ao artista berlinense Friedrich Vogel uma xilogravura para o frontispício d’O nascimento da tragédia. A vinheta mostra o Prometeu desacorrentado no momento da libertação. Os grilhões estão cerrados, o abutre agonizante é morto, e Prometeu está pronto para se erguer em liberdade. Nietzsche associa a imagem de Prometeu à "seriedade e urgência" de sua obra (GT/NT, "Prefácio a Richard Wagner"). Em conexão com "aquele abutre a roer o grande amigo dos homens que foi Prometeu" (GT/NT, $\S 3, K S A 1.36)$, esse mito nos lembra que o sofrimento é próprio à existência. Por essa razão, 
Heit, H.

o Prometeu desacorrentado de $O$ nascimento da tragédia glorifica o orgulho agressivo e o pecado ativo do criador titânico, mas também evoca a consciência trágica dos gregos, pela qual "o indivíduo a lutar titanicamente" em sua busca de sentido e poder se mantém cativo na "necessidade inevitavelmente requerida do sacrilégio" (GT/NT, $\S 9, K S A$ 1.69).

A adoção por Marx de Prometeu é menos trágica e levemente unilateral em sua ênfase no aspecto emancipatório e liberador do mito. Ele insere o deus titânico juntamente com Hume e Epicuro e com a defesa por estes da razão humana e da filosofia contra as demandas dogmáticas da religião. A radical rejeição por Prometeu do mundo divino (haplô logô, tous pantas echthairô theous - numa palavra: odeio todos os deuses) é para Marx a confissão central da filosofia, "seu próprio externar-se contra todos os deuses celestes e terrenos, que não consideram a autoconsciência humana como divindade suprema"13. Prometeu é, por isso, "o mais nobre santo e mártir no calendário filosófico"14, cuja oposição à crença dogmática serve como exemplo para os que aspiram à liberdade humana. Nietzsche observa o caráter trágico do fundamento prometeico da cultura humana. Prometeu simboliza a emancipação humana por meio da razão autoconfiante e da tecnologia, mas o mito também já indica o que Horkheimer e Adorno mais tarde chamarão de Dialética do esclarecimento. A civilização humana está inocentemente emaranhada na culpa. Mas é muito instrutivo que na seleção da imagem de capa ao seu primeiro livro, ele escolheu uma cena do mito que enfatiza o momento emancipatório dessa dialética.

13 Marx, 1843, p. 262.

14. Marx, 1843, p. 262.

152 | Cad. Nietzsche, Guarulhos/Porto Seguro, v.39, n.3, p. 141-174, setembro/dezembro, 2018. 


\section{O ultrapassamento da religião é o primeiro passo para a emancipação}

$\mathrm{O}$ mito de Prometeu e sua rebelião contra os deuses conduzem a um quarto - e de certo modo óbvio - aspecto em comum entre Marx e Nietzsche. Ambos partem de uma crítica fundamental à religião cristã, e ambos têm por inspiração básica as obras de Ludwig Feuerbach. Em 1861, Nietzsche acrescentou A essência do cristianismo (Das Wesen des Christentums, 1841) numa lista de desejos de aniversário ${ }^{15}$. Não sabemos o que sua mãe respondeu a isso, nem mesmo existe a certeza de que Nietzsche tenha possuído o livro. Mas uma carta a seus amigos Krug e Pinder, com data de 27 de abril de 1862, é claramente redigida no espírito de Feuerbach e termina com as palavras: "Com graves dúvidas e lutas a humanidade se torna masculina: ela reconhece em si mesma 'o início, o meio e o fim da religião.' Saudações, seu Fritz $^{\mathbf{1 6}}$. Tanto as metáforas de desenvolvimento quanto o referido drama de acontecimentos apontam para o texto de Feuerbach, com base no qual Nietzsche também parafraseia uma passagem central: "O homem é o início da religião, o homem é o centro da religião, o homem é o fim da religião" ${ }^{17}$. Com essa reconstrução antropogênica do religioso, nem a não-existência de Deus é provada, nem a função histórico-cultural da religião é diretamente negada. Em vez disso, a ideia central é a de que a religião é uma projeção inconsciente que, em sua ingenuidade, não seria apropriada para um adulto ${ }^{18}$. Com base nessas e outras leituras semelhantes, como a de Das Leben Jesu, de David Friedrich Strauss em 1865, Thomas Brobjer assume que Nietzsche teria perdido a fé entre 1861 e $1865^{19}$. Dali em diante,

15 Historische Kritische Ausgabe, Werke, 1933-1942: BAW I, 251.

16 Carta de 27 de abril de 1862, KSB 1. 202.

17 Feuerbach, 1841, p. 218.

18 Feuerbach, 1841, p. 218.

19 Brobjer, 2008, p. 43.

Cad. Nietzsche, Guarulhos/Porto Seguro, v.39, n.3, p. 141-174, setembro/dezembro, 2018. 
Heit, H.

passa a olhar a religião como uma aquisição inconsciente, que concebe o cosmos como algo humano, sem reconhecer a nós mesmos como autores dessa interpretação criativa.

Numa de suas primeiras ponderações sobre a sua própria obra, Marx revela compreender seu pensamento como uma radicalização da crítica à religião proposta pelos novos hegelianos como Feuerbach. A "crítica à religião" é a pressuposição de toda crítica ${ }^{20}$, não só porque ela expõe a religião como projeção humana, mas também porque nessa projeção torna visível a reinvindicação de uma vida melhor nessa projeção. "A miséria religiosa é, por um lado, a expressão da miséria real e, por outro, o protesto contra a miséria real"21. É por isso que Marx explica o impulso messiânico numa versão secularizada: "A abolição da religião como felicidade ilusória do povo é o requisito para a sua verdadeira felicidade. A demanda para se renunciar às ilusões sobre sua condição é a demanda a que se renuncie a uma condição que se valha de ilusões" ${ }^{\text {"22 }}$. Com base no contraste entre a felicidade ilusória na religião e a miséria real do povo, Marx deduz uma demanda prática que transponha a reivindicação de felicidade das ilusões religiosas para o reino da realidade. Assim, é preservado o ideal que é prometido na religião: ele deve ser realizado. "A crítica à religião termina com a doutrina de que o homem é o ser supremo para o homem, ou seja, termina com o imperativo categórico de reverter todas as condições em que o homem se faz um ser degradado,

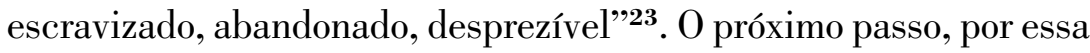
razão, deve ser dado tão-somente na prática, seu objetivo sendo a abolição do sofrimento desnecessário e a realização da liberdade material.

20 Marx, 1844a, p. 378.

21 Marx, 1844a, p. 378.

22 Marx, 1844a, p. 379.

23 Marx, 1844a, p. 385.

154 | Cad. Nietzsche, Guarulhos/Porto Seguro, v.39, n.3, p. 141-174, setembro/dezembro, 2018. 


\section{As críticas devem operar para além de Bem e Mal}

Assim como Nietzsche, Marx não tem interesse em justificativas filosóficas de certos pressupostos ou preconceitos morais. Sua compreensão da filosofia prática difere de tais ambições disseminadas. Além disso, eles não procuram argumentar nem pretendem fazê-lo de um ponto de vista crítico de uma moralidade superior. No prefácio a $O$ capital (Das Kapital), Marx enfatiza que, se por um lado ele de modo algum esboça um retrato cor-de-rosa dos capitalistas e donos de terra, por outro, sua crítica não é moralmente direcionada às ações de pessoas, mas contra as funções sistêmicas que elas representam como portadoras de certas relações de classe e interesses ${ }^{\mathbf{2 4}}$. Se o cerne do programa de pesquisa marxiana está na convicção da primazia da economia, então uma drástica mudança na situação humana só pode mesmo advir de uma mudança nas condições socioeconômicas. Dessa pressuposição surge a atitude frequentemente vista como negativa da parte de Marx em relação à moralidade. Para Marx, a exploração do trabalho não é um ato moralmente repreensível, próprio ao egoísmo de capitalistas supostamente maus. Ele reconhece aí um efeito de socialização funcional, e - consequentemente - não se propõe a corrigir essa situação mediante apelos morais. "Os comunistas de modo algum pregam moralidade", escreveu com Engels em $A$ ideologia alemã , porque "ao contrário, eles sabem muito bem que o egoísmo, assim como o sacrifício, é uma forma necessária de forçar indivíduos sob certas condições" ${ }^{25}$. Dessa atitude resulta não apenas a delimitação regular de argumentos morais ou religiosos contra o capitalismo no Manifesto e alhures, mas também na obra posterior, de autoria de Engels, Do socialismo utópico ao socialismo científico (1880). Com base no pressuposto de que agentes no seio da economia capitalista não agem de maneira livre e autodeterminada,

24 Marx, 1867, p. 16.

25 Marx \& Engels, 1846, p.229.

Cad. Nietzsche, Guarulhos/Porto Seguro, v.39, n.3, p. 141-174, setembro/dezembro, 2018. 
Heit, H.

mas realizam funções institucionais, o criticismo moral encontra-se fora de lugar. Por certo que no seio desses mecanismos funcionais existe um âmbito de ação que pode ser usado de um modo moral, filantrópico, ou impiedoso, ou criminoso. As regras do próprio jogo, contudo, escapam do acesso responsável de todos os jogadores isolados.

No caso de Nietzsche, em geral se concorda que ele tentou ocupar um lugar para além de bem e mal e que suas críticas não são pensadas em seu teor moral. Em $O$ Anticristo ele afirma: “Abri a cortina da corrupção do homem. Essa palavra, em minha boca, está protegida ao menos contra uma suspeita: a de conter uma acusação moral ao homem. É entendida - gostaria de sublinhá-lo mais uma vez - isenta de moralina: e isso em tal grau, que essa corrupção me é sentida mais fortemente ali onde até agora mais conscientemente se aspirou a "virtude", a "divindade" (AC/AC, § 6, KSA 6.172). Como ocorre em Marx, pode bem haver uma moralidade a subjazer à crítica à moralidade por Nietzsche (Van Tongeren), mas esse é um tópico que veremos mais tarde.

\section{Ambos empregam uma hermenêutica da suspeita}

Em vez de eles próprios argumentarem moralmente, ambos tentam decifrar as ideologias interessadas em suas motivações ocultas. Ambos empregam a questão "cui bono" (a quem beneficia?)" como a ferramenta heurística mais ponderosa para se compreender todos os tipos de instituições, de práticas, sermões ou tratados: "a que moral isso (ele) pretende chegar? (JGB/BM $\S 6, K S A 5.20)$. Com um certo orgulho, Nietzsche admite que suas obras tem sido chamadas de uma "escola da suspeita" (MA I/HH I, Prefácio, § 1. KSA 2.13). Creio ser justo observar que também Marx foi membro dessa escola. Numa descrição de seu método crítico à ideologia, ele observa: “Da mesma forma como não se julga o que um indivíduo é pelo que ele pensa de si mesmo, nem se pode julgar uma tal época de mudança com base em

156 | Cad. Nietzsche, Guarulhos/Porto Seguro, v.39, n.3, p. 141-174, setembro/dezembro, 2018. 
sua consciência, mas sim deve-se ser consciente das contradições da vida material, do conflito existente entre as forças produtivas sociais e as relações produtivas" "26. Enquanto Nietzsche explica o grau de moralidade de um filósofo (ou cultura) individual com referência à "hierarquia de seus mais íntimos impulsos e afetos" (JGB/BM, § 6, $K S A$ 5.20), Marx observa que os pensamentos dominantes de uma sociedade são os pensamentos dominantes da classe dominante em sua tentativa de "apresentar seus interesses como se fossem os interesses comuns de todos os membros de uma sociedade" ${ }^{27}$. Enquanto a referência fisiopsicológica a impulsos e afetos obviamente difere do enfoque de Marx a fatores socioeconômicos, ambos empregam uma heurística da suspeita, a separar pensamentos dominantes de verdades universais, e ambos apontam para o que consideram como o real subjacente à vida real e material. Existem paralelos entre a crítica desconstrutiva de Marx à ideologia e os procedimentos genealógicos de Nietzsche, embora os diferentes pressupostos não devam ser subestimados $^{28}$. Isso me conduz às minhas próximas duas teses.

\section{Ambos defendem uma antropologia naturalizada}

As hermenêuticas da suspeita de Marx e de Nietzsche ligamse a uma naturalização e - como abordarei na próxima tese - a uma historicização da humanidade. "A primeira premissa de toda a história humana", enunciam Marx e Engels em A ideologia alemã é, por óbvio, a existência de seres humanos individuais. Assim, o primeiro fato a ser estabelecido é a organização física desses indivíduos e sua consequente relação com o restante da natureza"29. Em contraste com uma longa e continuada tradição de modelos idealistas ou dualistas,

26 Marx, 1859, p. 9.

27 Marx \& Engels, 1846, p. 47.

28 Marti, 1994, p. 501s. Confira também Saar, 2007, p. 117.

29 Marx \& Engels, 1846, p. 20s. 
Heit, H.

Marx e Engels integram o homem e suas faculdades cognitivas "mais elevadas" no contexto contínuo da natureza. As capacidades de uma intervenção intencional bem como de uma comunicação, reflexão e introspecção podem ser entendidas no contexto da natureza humana. A constituição genérico-biológica dos seres humanos, em especial a separação da cabeça e da mão, capacita esses seres vivos a se envolver numa interação dirigida com a natureza, e entenda-se, pelo trabalho. Marx "subordina o trabalho de uma forma que o faz pertencer exclusivamente ao homem"30. O homem pode e tem de trabalhar; ele é compelido e é capaz de apropriadamente transformar e adquirir natureza interna e externa. $\mathrm{O}$ engajamento humano com a natureza não é determinado pelos instintos, nem é governado por alguma razão absoluta e irrestrita. A ação humana pertence à natureza e é parte da natureza, mas de modo valorativo e intencional. Como ser físico necessitado de nutrição natural, o homem realiza a sua finalidade "também no meio natural"31. No trabalho conectam-se a existência natural e a percepção finalista e consciente. Na história da humanidade, por essa razão, o ato de pensar surge no debate concreto acerca da natureza e em última instância se mantém atrelado a ela. Como resultado, o homem ao mesmo tempo se aparta do contexto da natureza. A questão do naturalismo é tópico amplamente discutido nos estudos sobre o filósofo. Os detalhes estão em aberto, mas não há razão para duvidar de que Nietzsche está entre aqueles que se opõem ao dualismo, derivam a linguagem humana e a consciência do corpo da necessidade social de comunicar, e defendem uma antropologia socionatural. Eu argumento, em outro momento, que Nietzsche percebe a humanidade como um ser natural de transcendência interna ao mundo ${ }^{32}$. Muito semelhante ao conceito de trabalho de Marx, a antropologia naturalizada de Nietzsche caracteriza o animal

30 Marx, 1867, p. 193.

31 Marx, 1867, p. 193.

32 Cf. Heit, 2016 e 2018.

158 | Cad. Nietzsche, Guarulhos/Porto Seguro, v.39, n.3, p. 141-174, setembro/dezembro, 2018. 
humano peculiar por sua capacidade de intervir, interagir, construir e projetar-se para o resto da natureza. Isso permite que o animal humano transforme seu mundo, para abrir novos espaços na natureza e preenche-los com sua própria ambição.

\section{Ambos propõem genealogias históricas num espírito transformador}

As genealogias naturalizadas de Nietzsche parecem diferir, de muitas importantes maneiras, das construções históricas de Marx, mais precisamente com relação às dívidas do último para com os conceitos hegelianos de estrutura e progresso. Marx avalia sua relação com Hegel muito adequadamente quando escreve no epílogo à segunda edição de $O$ capital: "A mistificação por que passa a dialética nas mãos de Hegel não o impediu de ser o primeiro a apresentar suas formas gerais de movimento, de maneira ampla e consciente. Em Hegel, a dialética está de cabeça para baixo"33. Entre as mistificações criticadas está a ideia hegeliana de que a realidade já é racional, porém Marx aceita a ideia processando a dialética historicamente. Numa das primeiras recepções da Fenomenologia do espírito, Marx observa que Hegel encontrou ali "somente a expressão abstrata, lógica, especulativa para o movimento da história, que ainda não é a história real do homem"34, porém Hegel não obstante reconhece a essência processual do ser (humano) e a "dialética da negatividade como princípio motor e gerador"35. Marx parece assumir que o processo histórico é um movimento reconhecível e passível de ser racionalmente descrito, muito embora Hegel se equivocasse quanto ao motor desse movimento. Assim como Hegel, contudo, ele vê uma certa legitimidade na história à medida que assume

33 Marx, 1867, p. 27.

34 Marx, 1844b, 570.

35 Marx, 1844b, p. 574.

Cad. Nietzsche, Guarulhos/Porto Seguro, v.39, n.3, p. 141-174, setembro/dezembro, 2018. 
Heit, H.

um desenvolvimento histórico-tecnológico que se dá em estágios e representa um progresso passível de ser reconhecido pelo resultado.

A essa altura Nietzsche e Marx parecem começar a divergir. A relação de Nietzsche com a dialética e a ideia de contradições produtivas é complexa, mas ele nega constantemente a existência de leis da história e o conceito de progresso e sucessão, que facilmente "conduz a uma idolatria do factual" (HL/Co. Ext. II, § 8, KSA 1.303) Essa é uma glorificação mítica da história, cujo uso para a vida é negado por Nietzsche. A ideia de genealogia está em contraste cabal com tais mitologias, e foi adotada por pensadores como Foucault, para escapar a essas implicações do conceito marxiano padrão de história. Nietzsche obviamente rejeitaria a expectativa econômica do marxismo, de acordo com a qual o desenvolvimento das forças produtivas desencadeado pelo capitalismo conduz necessariamente a um mundo melhor ${ }^{36}$ - se é que era isso o que pensava Marx. Além do mais, Nietzsche se concentra em psicologia e cultura, enquanto Marx mantém o foco em economia e sociedade, e, não obstante sua referência ocasional a "obrigações" econômicas $(G M / G M$ II, § 6, $K S A 5.300$ ss.), suas genealogias não são reduções socioeconômicas.

Se se compreende o marxismo principalmente (ou meramente) como hegelianismo materialista e reducionista, o procedimento então parece de fato ser uma “deificação da história', mesmo em se tendo hegelianos ateístas como Marx e Engels"37. Ao inserir Hegel de ponta-cabeça, contudo, a atenção migra da racionalidade abstrata para a realidade concreta. Proponho-me a ler Marx de maneira menos dogmática. O passado, e certamente o futuro, não são determinados por um mecanismo subjacente a desenvolver-se virtualmente por si mesmo. Já os avanços técnicos e os conflitos sociais reais (prometeicos) inauguram possibilidades que podem ser realizadas por pessoas reais em lutas políticas de um modo ou de outro. As narrativas de Marx

36 Waibl, 1989, p. 27.

37 Adorno, 1966, p. 315.

$160 \mid$ Cad. Nietzsche, Guarulhos/Porto Seguro, v.39, n.3, p. 141-174, setembro/dezembro, 2018. 
sobre os estágios produtivos na história da humanidade poderiam ser lidas como genealogias, que são pensadas para encorajar alguma ação. Se a concepção prática da verdade por Marx é aplicada à sua filosofia da história, tem-se aí mais do que meramente uma reversão materialista de Hegel, como a que pode ser encontrada, por exemplo, na obra de Feuerbach. Tanto Hegel quando Feuerbach compreendem a realidade, de acordo com Marx, "somente sob a forma do objeto [...] não como atividade humana sensual, prática, não subjetiva"38. A realidade não é simplesmente oposta a nós como objeto cognitivo, mas ao mesmo tempo é produto de prática humana. Quanto a esse aspecto, o processo histórico não pode em última instância ser um automatismo legítimo, mas sim a história é feita, seja de maneira consciente ou inconsciente, voluntária ou involuntária. Marx percebe que não estamos simplesmente a refletir sobre nosso tempo com uma contemplação passiva, mas nós mesmos somos parte praticamente efetiva desse tempo. Interpretação é atividade.

\section{O capitalismo é (parte d) o problema}

Com essa tese, chegamos ao cerne de nossa comparação entre Nietzsche e Marx. Penso estar claro que Nietzsche não merece a acusação de Franz Mehring, de ser o "filósofo social do capitalismo"39. Na verdade, mesmo Georg Lukács percebe que Nietzsche de início se encontra mais perto de versões do "anticapitalismo romântico" ". Nietzsche não usa o termo "capitalismo" e raramente fala em "capital"; o mais provável é que não tenha dele nenhum conceito, e certamente não fornece nenhuma análise sistemática da economia moderna. Como resultado, ele simplesmente identifica o capitalismo com a ganância. Nietzsche rejeita a busca de ganho material constitutivo

38 Marx, 1845, p. 5.

39 Mehring, 1891, p. 188.

40 Lukács, 1954, p. 37; cf. também Waibl, 1989, p. 31 e Marti, 1994, p. 499. 
Heit, H.

do capitalismo como um falso valor cultural e o vê como expressão de necessidades inferiores e de decadência cultural $^{\mathbf{4 1}}$.

Já que não pode imaginar um estado de trabalho livre e digno, ele aconselha aos "trabalhadores da escravidão fabril" a não mais servir como "parafusos de uma máquina” (M/A, § 206, KSA 3.183). Nietzsche, contudo, não considera o socialismo uma saída, uma vez que ele é apenas a expressão generalizada do mesmo ressentimento pelo qual "se inveja o vizinho rico" (M/A, § 206, KSA 3.184). A causa do capitalismo é, para Nietzsche, o desejo institucionalizado e a busca insaciável de lucro na "indústria cultural": em sua forma presente, esse último é a modalidade mais desprezível de existência que já houve. Aqui a lei da necessidade funciona de modo simples: "uma pessoa quer viver e tem de se vender" (FW/GC, $\S 40, K S A 3.407)$. Entre as consequências do capitalismo encontra-se o socialismo e a emancipação da mulher (JGB/BM, $\S 239, K S A 5.176$ ss.), bem como a "unificação econômica da Europa" (Nachlass/FP 1887-88, 11 [235], $K S A 13.92$ s.) e o advento das guerras nacionalistas (Nachlass/FP 1888, 15 [38], KSA 13.431). Apesar desses efeitos civilizatórios, ele se volta incisivamente contra o disseminado "otimismo de teorias de estado e teorias da economia" (Nachlass/FP 1869-70, 3 [8], KSA 7.61). De modo semelhante a Marx, Nietzsche reconhece o capitalismo como um sistema destrutivo. Onde Nietzsche compreende os "sintomas de um completo extermínio e desenraizamento da cultura" como consequência de "uma economia grandiosa e desprezível (SE/Co. Ext. III, § 4. KSA 1.367;), Marx fala da necessidade da burguesia de "constantemente revolucionar todas as relações sociais" $"$. No plano ideológico, Nietzsche observa um disseminado e irresponsável "caráter apologético", que perdeu toda e qualquer capacidade de definir um objetivo cultural e proporcionar qualquer sentido e valor para nossa atividade, que está em crescimento cada vez maior: "ao

41 Confira Nachlass/ FP 1881, 11 [180], KSA 9.471.

42 Marx \& Engels, 1848, p. 465.

162 | Cad. Nietzsche, Guarulhos/Porto Seguro, v.39, n.3, p. 141-174, setembro/dezembro, 2018. 
que parece, o que ainda está ativo na mente sem que seja consumido na transmissão do próprio e grande mecanismo de aquisição e poder tem como tarefa única defender e desculpar o presente (WB/Co. Ext. IV, $K S A$ 1. 462.). Nessa apologia do factual, o tempo presente prova estar fundamentalmente carente de quaisquer meios de orientação consciente e autodefinida: "Nossa época, embora fale tanto de economia, é dissipadora: dissipa o que é mais precioso, o espírito" $(M / A, \S 179, K S A 3.157 \mathrm{~s}$.$) .$

De acordo com Marx, a força motriz e o objetivo da circulação capitalista de bens não são o aumento da qualidade de vida das pessoas ou o desfrute da riqueza, mas a maximização continuada de valor. Isso também revela a conexão sistemática entre o funcionamento do capitalismo e a ética de funcionamento ascético descrito por Max Weber, que aqui está a seguir a inspiração nietzschiana. O mercado capitalista satisfaz as necessidades materiais de participantes financeiramente bem-sucedidos de maneira bastante exitosa, mas também apenas incidental. Nosso interesse pelas coisas se torna uma função econômica. Um suprimento qualitativo e emocionalmente satisfaciente de bens não é o objetivo, e sim apenas um instrumento de maximização de lucro. Que bens sejam produzidos ou que serviços sejam proporcionados não é, em última instância, algo importante em si mesmo, mas o é com relação ao retorno econômico. “O valor de uso, por essa razão, jamais é tratado como finalidade imediata do capitalista. Nem o lucro individual, mas tão-somente o inquieto movimento de vencer"43. Os atores neste movimento, sejam eles ricos ou não, atuam como funções e obedecem a um dado mecanismo. Em seu poder de governo, o capitalismo é tão totalitário quanto a gravitação ou a mortalidade, embora seja, obviamente, um ordenamento histórico e feito pelo homem. Assim, o capitalismo não é uma economia de injustiça, desperdício e alienação, mas seu próprio mecanismo estrutural elementar solapa a liberdade

43 Marx, 1867, p. 168.

Cad. Nietzsche, Guarulhos/Porto Seguro, v.39, n.3, p. 141-174, setembro/dezembro, 2018. 
Heit, H.

dos súditos que nele estão a atuar. Os seres humanos regridem a "máscaras de personagem" e "personificações" de suas funções econômicas ${ }^{\mathbf{4 4}}$. Em última instância, Marx é enfático ao afirmar que o capitalismo, não obstante todos os efeitos libertadores e seu pathos individualista, representa um obstáculo fundamental à liberdade de súditos independentes e vigorosos. Não obstante seus poderes emancipatórios, sob condições capitalistas nem o pobre nem o rico são, por esse motivo, sujeitos libertos de sua própria história. No capitalismo, bem como em todas as visões anteriores de sociedade, as pessoas entram em "condições necessárias que são independentes de sua vontade" ${ }^{\text {45 }}$. Nesse sentido, Marx concorda com Nietzsche no sentido de que o capitalismo não tem objetivo cultural outro que não o lucro cada vez maior, e isso conduz à alienação, permanece "préhistória" (Marx) e não define nenhum horizonte, nenhum para-quê.

\section{O mais elevado objetivo cultural não é a igualdade, mas a liberdade}

À luz dessa compreensão mais ampla das críticas de Marx e de Nietzsche ao capitalismo, poderíamos considerar seus respectivos ideais, utopias ou tentativas de uma filosofia do futuro por um ângulo diferente. Pela sabedoria popular, Nietzsche e Marx encontram-se na mais aguda contradição quando se trata da questão de ideais e perspectivas. Enquanto Marx se diz favorável às massas, Nietzsche é visto como o proponente do indivíduo, da diferença e das hierarquias. A esse respeito Urs Marti enuncia claramente: para Nietzsche o socialismo é fundamentalmente "uma ameaça à ordem social existente, e tanto mais à ordem social desejável" 4 . Na verdade, Nietzsche vez por outra descreve o socialismo "como a tirania do menor e do mais

44 Marx, 1867, p. 100.

45 Marx, 1859, p. 8.

46 Marti, 1993, p.143.

$164 \mid$ Cad. Nietzsche, Guarulhos/Porto Seguro, v.39, n.3, p. 141-174, setembro/dezembro, 2018. 
estúpido, do superficial, do invejoso e dos atores de três quartos" - em suma, como "a conclusão das ideias modernas" (Nachlass/FP 1885, 37[11], KSA 11.586). No aforismo 40 d'A gaia ciência, ele atribui o surgimento do socialismo à "vulgaridade manufatureira" da "cultura industrial" governada por ganância e sorte. O socialismo não é visto como alternativa a essa cultura, mas como sua generalização; ele é consequência da mesma ganância, no que chamamos hoje de "flautas dos aliciadores socialistas que querem inflamar os trabalhadores com doidas esperanças" (M/A, § 206, KSA 3.183ss.). Além de algumas objeções práticas, Nietzsche obviamente não compartilha os objetivos dos políticos socialistas de seu tempo. "O socialismo se baseia na decisão de igualar as pessoas e de ser justo com todos: é a mais elevada moralidade." (Nachlass/FP 1877, 21[43], KSA 8.373). Essa decisão moral é problemática, porque inclui a negação da individualidade e expressa o ressentimento e a ganância material. Nietzsche duvida de que dos estados petrificados e "ordenados, que são demandados pelo socialismo", algo de grande possa surgir, o que é problemático já que "a humanidade não tem objetivos outros que não grandes homens e grandes obras" (Nachlass/FP 1877, 25[1], KSA.481ss.). Embora isso possa parecer cínico em relação aos fracos e pequenos, vale a pena notar que Nietzsche define grandes homens e grandes obras como um objetivo cultural e societário. Entendida como uma ambição compartilhada pela humanidade, e não como a defesa interessada de privilégios sociais, alcançar grandes homens (e mulheres!) e grandes metas requer um contexto cultural que valorize e apoie indivíduos excepcionais. O socialismo, por outro lado, pelo menos como Nietzsche o entendeu, é o objetivo de ser tal qual a vaca de um rebanho feliz, o ideal do último homem, que despreza e teme a diferença e a excepcionalidade. "Todo mundo quer a mesma coisa, todos são iguais: quem sente de modo diferente entra voluntariamente no manicômio" (ZA/ZA, Prólogo, § 5, KSA 4.20). 
Heit, H.

Max Horkheimer desculpa as observações depreciativas de Nietzsche acerca do socialismo com três argumentos: em primeiro lugar ele observa que as críticas de Nietzsche a políticos socialistas ressentidos é de certo modo justificada: "Ele não conhecia Marx, mas somente a Social Democracia de seu tempo; ele não a tomava como de todo errada." Horkheimer aponta que as objeções de Nietzsche se aplicam às concepções ressentidas, nacionalistas e mesquinhas dos socialdemocratas do século XIX, como Ferdinand Lassalle. A segunda desculpa é que Nietzsche, em seu justificado "ódio contra um mundo governado pela economia", equivocou-se quanto "ao caráter histórico do trabalho". Nietzsche não podia imaginar um mundo sem a escravidão das massas porque não podia imaginar que o trabalho pudesse perder seu caráter espoliativo. Entretanto, e esta é a terceira desculpa de Horkheimer, o potencial crítico do filósofo se mantém significativo: "Por detrás de suas formulações aparentemente misantrópicas não está tanto esse erro quanto está o ódio contra o caráter passivo e conformista, paciente, submisso e reconciliado com o presente"47. Além dessas considerações, quero salientar outros dois aspectos, que podem propiciar um diálogo produtivo entre Marx e Nietzsche, inclusive acerca da questão do futuro da humanidade.

Em primeiro lugar, eu duvido de que o socialismo pensado em termos de conformismo e igualdade seja o objetivo central de Marx. Na verdade, são demandados a propriedade social, bem como uma distribuição racional e justa. Mas Marx não é nem um igualitarista nem um amoralista. Marco Iorio corretamente ressalta que "no alto do cânone de valores de Marx encontra-se a liberdade ou a emancipação de um homem"48. A sociedade capitalista moderna produz o ideal de livre autodeterminação tanto quanto solapa a sua realização. Marx afirma que tal discrepância entre a alegação e a realidade,

47 Horkheimer, 1937, p. 409.

48 Iorio, 2012, p. 239.

$166 \mid$ Cad. Nietzsche, Guarulhos/Porto Seguro, v.39, n.3, p. 141-174, setembro/dezembro, 2018. 
com o auxílio da crítica imanente, opera em contraste com o pathos moderno tanto quanto as possibilidades econômicas de sociedades desenvolvidas com os prospectos reais de autodeterminação e felicidade. Por essa razão, uma contínua emancipação das pessoas só pode ser realizada se elas "racionalizarem seu metabolismo com a natureza, trazendo-o para o controle coletivo, em vez de ser por ele governadas como por um poder cego"49. Só então as pessoas poderiam tornar-se sujeitos de sua história. Ser sujeito de sua história não significa de algum modo lidar com restrições externas, mas determiná-las o máximo possível. Uma vez que grande parte dessas restrições advém da natureza, e não das instituições sociais, elas só podem ser remediadas pelo interesse do indivíduo de maneira social. A meu ver, este é o conceito de liberdade em Marx: "No lugar da velha sociedade burguesa com suas classes e antagonismos de classe, tem-se uma associação na qual o livre desenvolvimento de cada um é a condição para o livre desenvolvimento de todos"50.

O objetivo e o destinatário centrais de uma sociedade liberta é, por essa razão, não o grupo, mas o indivíduo. Contra as fantasias de coletivização de muitos políticos socialistas, que esperam ser capazes de dissolver a distinção entre necessidades individuais e gerais, Marx traz para seu foco de atenção a reivindicação de desenvolvimento individual. Para Marx, a ideia de coletivização sob o ditame do trabalho está entre as ideias primitivas de um socialismo utópico primitivo, cuja literatura é "necessariamente reacionária no conteúdo. Ela ensina o ascetismo geral e o igualitarismo cru"51. Sob tais condições, o livre desenvolvimento de cada qual não se faz possível. Filosoficamente falando, Marx admite que o geral e o particular jamais podem ser idênticos e alinha-se ao indivíduo. A sociedade liberta não consiste na falsa subordinação do indivíduo

49 Marx, 1894, p. 828.

50 Marx \& Engels, 1848, p. 482.

51 Marx \& Engels, 1848, p. 489.

Cad. Nietzsche, Guarulhos/Porto Seguro, v.39, n.3, p. 141-174, setembro/dezembro, 2018. 
Heit, H.

ao coletivo. A realização de tal sociedade se mantém dependente da ação consciente dos homens.

De acordo com Nietzsche, uma "sociedade livre" é, estritamente falando, uma contradictio in adjecto. Minha segunda consideração é a de que Marx concordaria com isso. Pelo menos, as reservas de Nietzsche em relação à ideia de sociedade livre podem ajudar a esclarecer o que Marx tem em mente. Contra as utopias igualitaristas de harmonia cristalizada, Nietzsche insiste em que um sujeito vivo inevitável e constitutivamente se mantém emaranhado em domínio e regulação, uma vez que apropriação, exploração e superempoderamento pertencem à "essência do ser vivente, como função orgânica básica" (JGB/BM, § 259, KSA 5.208). Christoph Türcke confere uma explicação clara a esse respeito quando corretamente nos pergunta: "Com toda a franqueza: Mesmo a mais racional regulação do metabolismo humano com a natureza seria capaz de erradicar completamente essas determinações da vida segundo Nietzsche? Não estão todos envolvidos na mais inócua extração de comida [... e] em todo processo educacional que, mesmo sob as condições mais favoráveis, não cessa de ser um processo de disciplinamento do animal no homem?"52 . Marx não apenas sabe que as condições têm de ser favoráveis. Em A ideologia alemã, ele enfatiza que um alto nível de desenvolvimento técnico e econômico é "um pré-requisito prático absolutamente necessário para o estabelecimento de uma sociedade liberal, já que sem ele só mesmo a escassez se generaliza, isto é, com a escassez recomeçariam as disputas para se obter os meios necessários, e toda a velha porcaria voltaria a emergir"53. Uma vez que não é possível se evadir ao contexto da natureza, a liberdade se mantém atrelada aos meios de organizar nossa vida:

52 Türcke, 1989, p. 105.

53 Marx / Engels, 1846, p.34 s.

168 | Cad. Nietzsche, Guarulhos/Porto Seguro, v.39, n.3, p. 141-174, setembro/dezembro, 2018. 
A liberdade nessa área só pode consistir no fato de que a pessoa socializada e os produtores associados racionalizam seu metabolismo com a natureza, trazendo-o para sob seu controle conjunto, em vez de ser por ele dominado ao modo de um poder cego, realizando-o com o menor esforço e sob as condições mais dignificadas e adequadas de sua natureza humana. Mas sempre restará um reino de necessidade. Para além dele se inicia o desenvolvimento do poder humano, que é considerado um fim em si mesmo, o verdadeiro reino da liberdade, que, contudo, pode florescer somente em se tomando o reino da necessidade como sua base. A redução da jornada de trabalho é a condição básica ${ }^{54}$.

O modo pelo qual o Marx tardio traduz considerações filosóficas fundamentais sobre os limites e a natureza da liberdade - em demandas políticas muito concretas, pragmáticas e realistas - lança uma nova luz sobre a compreensão de Nietzsche sobre a escravidão em Humano, demasiado humano: "Assim como em todos os tempos, agora também os homens estão divididos entre escravos e livres, pois quem não tem dois terços de seu dia para si mesmo é um escravo; deixemos que ele seja o que poderia ser de qualquer modo: estadista, homem de negócios, oficial, erudito" (MA I/ HH I, § 283, KSA 2.231s.).

\section{Filosofia experimental: Verdade é práxis}

Em um apontamento tardio, Nietzsche fala do fato de se poder reconhecer uma filosofia de seu tipo pelo quanto de verdade ou mesmo de erros ele ousa considerar e a chama de "filosofia experimental, tal como eu a vivencio" (Nachlass/FP 1888, 16[32], KSA 13.492s.). Nietzsche assim procede ao manuseio ousadamente experimental de modelos fundamentais de interpretação do mundo como traço característico de sua filosofia e de seu modo de vida, que, não obstante a dimensão artística de sua investigação, não pode ser compreendido como expressão da frivolidade. Experimentos são tentativas sérias, não raro dispendiosas e perigosas, mas realizadas com espírito

54 Marx, 1894, p. 828.

Cad. Nietzsche, Guarulhos/Porto Seguro, v.39, n.3, p. 141-174, setembro/dezembro, 2018. 
Heit, H.

aberto. Experimentamos porque não está determinado o que se deve pensar ou fazer. N'A gaia ciência ele exalta essa abordagem como consequência da concepção afirmadora de vida e libertadora "de que a vida deve ser um experimento daquele que busca conhecer e não um dever; uma fatalidade, não uma trapaça" $(F W / G C, \S 324$, KSA 3. 552).

Esse é o espírito que eu encontro também na décima-primeira tese de Marx contra Feuerbach: "Até agora, os filósofos limitaram-se a interpretar o mundo de diferentes maneiras, trata-se doravante de transformá-lo"55. No lugar da sutileza analítica e da profundidade especulativa, Marx, assim como Nietzsche, volta a atenção para a realidade concreta da vida e para a eficácia viva do pensamento. Por essa razão, a famosa tese formula uma mudança de objetivo, de uma análise para uma intervenção. Isso não deveria ser confundido com um ativismo insensato, já que uma intervenção, caso pretenda ser eficiente ou efetiva, requer interpretação. Em vez disso, trata-se de uma mudança na autocompreensão da filosofia e no objetivo do esforço intelectual.

A questão sobre se a verdade objetiva pode ser atribuída ao pensamento humano não é uma questão teórica, mas uma questão prática. É preciso provar a verdade, isto é, a realidade e o poder, o este-lado-de-cá do pensamento, na prática. A disputa sobre a realidade ou não realidade do pensamento que é isolada da prática é questão puramente escolástica ${ }^{56}$.

A verdade das questões menores como a validade de minha leitura de Marx e Nietzsche, ou de grandes questões como a possibilidade de uma sociedade liberada ou o além-do-homem depende de seu poder de convencer, de mudar, de se tornar efetivo ou real. Não conhecemos por antecipação. Não há nenhuma outra maneira de dizer a verdade a partir do erro. Por essa razão, Nietzsche

55 Marx, 1845, p. 7.

56 Marx, 1845, p. 5.

$170 \mid$ Cad. Nietzsche, Guarulhos/Porto Seguro, v.39, n.3, p. 141-174, setembro/dezembro, 2018. 
convoca todos os tipos de objeções e de ceticismo, enquanto "me for permitido responder: “Tentemos"” $(F W / G C, \S 51, K S A$ 3.415).

\begin{abstract}
The aim of this paper is to point out significant similarities and productive dissonances between Marx and Nietzsche. My thesis is that these two thinkers have much more in common as is usually acknowledged. After a prove that Nietzsche most certainly know Marx, I develop several aspects of commonality. Both pursue philosophical projects of critical transformation, employ a hermeneutics of suspicion beyond good and evil, propose a naturalized anthropology and historical reconstructions. The final passages discuss their respective views on capitalism and socialism. The similarities as well as the differences between Marx and Nietzsche could serve as a productive resource and inspiration in our contemporary attempts to understand the world we live in.

Keywords: Truth, Practice, Freedom, Transformation, Capitalism, Socialism
\end{abstract}

\title{
Referências bibliográficas
}

ADORNO, Theodor W. Negative Dialektik. Frankfurt am Main: Suhrkamp, 1982.

BROBJER, Thomas H. "Nietzsches Knowledge of Marx and Marxism". In: NietzscheStudien, Berlim, n. 31, p. 298-313, 2002.

. Nietzsche’s Philosophical Context. An Intellectual Biography, Urbana: University of Illinois Press, 2008.

BROWN, Alexander. "In Defence of Reason? Friedrich Nietzsche in Thomas Mann's Nietzsches Philosophie im Lichte unserer Erfahrung and Georg Lukács' Die Zerstörung der Vernunft". In: Nietzsche-Studien, Berlim, n.47, p. 379-397, 2018.

CAMPIONI, Giuliano; D'IORIO, Paolo; FORNARI, Maria Cristina; o FRONTEROTTA, Francesco \& ORSUCCI, Andrea (orgs.). Nietzsches persönliche Bibliothek. Berlim: de Gruyter, 2003.

FEUERBACH, Ludwig. Das Wesen des Christentums (1841). Frankfurt/Main: Suhrkamp, 1971.

Cad. Nietzsche, Guarulhos/Porto Seguro, v.39, n.3, p. 141-174, setembro/dezembro, 2018. 
Heit, H.

HEIT, Helmut. "Naturalizing Perspectives. On the Epistemology of Nietzsche's Experimental Naturalizations". In: Nietzsche Studien, Berlim, vol. 45, p. 5680, 2016.

. „Der Mensch als ,Gesellschaftsbau'. Nietzsches Physio-Politische Anthropologie der Freiheit“. In: Internationales Jahrbuch für Philosophische Anthropologie. Berlim/Boston, vol. 7/2018, p. 101-118, 2018.

HERODOTUS . Herodoti Historiae. Org. por N. G. Wilson. Oxford: Oxford University Press, 2015.

HORKHEIMER, Max „Bemerkungen zu Jaspers“ ,Nietzsche““” In: Zeitschrift für Sozialforschung. Frankfurt, vol. VI/2, p.407-414, 1937.

IORIO, Marco. Einfïhrung in die Theorien von Karl Marx. Berlim: de Gruyter, 2012.

JACOBY, Leopold. Die Idee der Entwickelung. Eine sozial-philosophische Darstellung. 2. ed. Vol. I, Zurique: Verlags-Magazin,1886.

KIDD, Benjamin. Principles of Western Civilisation. Nova York: The Macmillan company, 1902.

LUKÁCS, Georg. Die Zerstörung der Vernunft. Band II. Irrationalismus und Imperialismus (1954). Darmstadt: Hermann Luchterhand Verlag, 1974.

LUKÁCS, Georg. Von Nietzsche zu Hitler oder: Der Irrationalismus und die deutsche Politik. Frankfurt/Main: Fischer Verlag, 1966.

MANN, Thomas. Nietzsches Philosophie im Lichte unserer Erfahrung (1947). Basileia: Schwabe Verlag, 2005.

MARTI, Urs. „Der grosse Pöbel- und Sklavenaufstand“. Nietzsches Auseinandersetzung mit Revolution und Demokratie. Stuttgart: Metzler, 1993.

. „Motive des romantischen Anti-Kapitalismus bei Nietzsche“. In: BORSCHE, T. (org.): „Centauren-Geburten“. Wissenschaft, Kunst und Philosophie beim jungen Nietzsche. Berlim/Nova York: de Gruyter, p. 489-502, 1994.

MARX, Karl. „Differenz der demokritischen und epikureischen Naturphilosophie nebst einem Anhange“. In: Institut für Marxismus-Leninismus beim ZK der SED, (ed.): Karl Marx - Friedrich Engels - Werke (MEW). Berlim: Dietz, 1968 ss., vol. 1, p. 257-373, 1844.

172 | Cad. Nietzsche, Guarulhos/Porto Seguro, v.39, n.3, p. 141-174, setembro/dezembro, 2018. 
. „Zur Kritik der Hegelschen Rechtsphilosophie. Einleitung“. In: $M E W$ Vol. 1, p. 378-391, 1844a.

MARX, Karl. „Ökonomisch-philosophische Manuskripte“. In: $M E W$, vol. 1, p. 475-588, 1844b.

. „Thesen über Feuerbach“. In: MEW, Vol. 3, p. 5-7, 1845.

1859.

. „Zur Kritik der politischen Ökonomie“. In: $M E W$, Vol. 13, p. 3-160,

. „Das Kapital. Kritik der politischen Ökonomie. Erster Band“. In: $M E W$, vol. 23, p. 3-802, 1867.

. „Das Kapital. Kritik der politischen Ökonomie. Dritter Band“ (editado postumamente por Friedrich Engels). In: MEW, vol. 25, p. 31-893, 1894.

MARX, Karl \& ENGELS, Friedrich. „Die deutsche Ideologie. Kritik der neuesten deutschen Philosophie in ihren Repräsentanten Feuerbach, B. Bauer und Stirner, und des deutschen Sozialismus in seinen verschiedenen Propheten“. In: $M E W$, vol. 3, p. 9-530, 1846.

MARX, Karl \& ENGELS, Friedrich. „Das Manifest der Kommunistischen Partei“. In: $M E W$, vol. 4, p. 461-493, 1848.

MEHRING, Franz (1891): „Zur Philosophie des Kapitalismus (Nietzsche)“. In: BERGNER, D. (org.). Franz Mehring. Aufsätze zur Geschichte der Philosophie. Frankfurt am Main: M. Röderberg Verlag, p. 188-198, 1975.

MONTINARI, Mazzino. „Nietzsche zwischen Alfred Baeumler und Georg Lukács“. In: MONTINARI, M. Nietzsche lesen. Berlim: de Gruyter, p. 169-206, 1982.

NIETZSCHE, F. Sämtliche Werke. Kritische Gesamtausgabe (KGW). Berlin/New York: Walter de Gruyter, 1967 - 1978.

. Nietzsche Briefwechsel. Kritische Gesamtausgabe (KGB). Berlin/New York: Walter de Gruyter, 1975.

. Sämtliche Briefe: Kritische Studienausgabe (KSB). Berlin/ New York: Walter de Gruyter, 1986.

. Sämtliche Werke. Kritische Studienausgabe (KSA). Berlin/New York: Walter de Gruyter, 1999. 
Heit, H.

. A gaia ciência. Trad. De Paulo César de Souza. São Paulo: Cia das Letras, 2001.

SAAR, Martin. Genealogie als Kritik. Geschichte und Theorie des Subjekts nach Nietzsche und Foucault. Frankfurt/Main: Verlag C.H. Beck, 2007.

SHAO, Lixin. Nietzsche in China. Nova York: Peter Lang Publishing, 1999.

TONGEREN, Paul van. Die Moral von Nietzsches Moralkritik. Studie zu „Jenseits von Gut und Böse" Bonn: Bouvier, 1989.

TÜRKE, Christoph. „Hölzernes Eisen“. In: Konkret. Zeitschrift für Politik und Kultur. Hamburgo, vol. 10/89, p. 102-106, 1989.

WAIBL, Elmar. Ökonomie und Ethik II. Die Kapitalismusdebatte von Nietzsche bis Reaganomics. Stuttgart-Bad Cannstatt: Frommann-Holzboog, 1989.

WEBER, Max. Max Weber. Werk und Person. Dokumente ausgewählt und kommentiert von Eduard Baumgarten. Mit Zeittafel und 20 Bildtafeln. Tübingen: Verlag J. C. B. Mohr, 1964. 